\title{
Fleeting Encounters \& Brick walls: Animating Embodied Literacies in Our Everyday Relations
}

\author{
RACHAEL BELL \\ University of New Brunswick \\ KATELYN COPAGE \\ University of New Brunswick \\ MATT ROGERS \\ University of New Brunswick \\ PAM WHITTY \\ University of New Brunswick
}

\begin{abstract}
Rachael, Katelyn, Pam and Matt take up Sara Ahmed's (2012) concepts of fleeting encounters and brick walls as they reflect on the feminist and decolonizing nature of their work. This paper is the product of months of conversation between the co-authors. Through the use of autoethnographical and participatory approaches, the authors seek to invite the reader into a co-constructed space where mutual support and inspiration shape the future actions of the participants as they grapple with their ethical responsibilities as learners and educators.
\end{abstract}

\section{Welcome to Our Conversational Space Rachael, Katelyn, Pam \& Matt}

We deeply appreciated the privilege of having been invited as provocateurs for the Language and Literacy Researchers of Canada (LLRC) 2017 pre-conference plenary panel. We are Rachael, Katelyn, Pam and Matt - critical literacies graduate students and professors at the University of New Brunswick Fredericton (UNBF), located on the unpurchased and unceded territory of the Wolastoqey peoples. The university itself is situated just above the Wolastoq River, now referred to as the Saint John River-renamed in 1604 by Samuel Champlain when he entered the Wolustoq River on the Feast of Saint Jean the Baptiste. Actions are now being taken to reclaim the river's original name.

At the LRRC pre-conference in 2017, we found a welcoming and engaging group of "exquisite conversationalists". Thank you for that. At that time, we collectively assembled our individual processes taking up Sara Ahmed's (2012) concepts of fleeting encounters and brick walls. Fleeting encounters and brick walls, then and now, materialize/d differently for each of us. Rachael, Katelyn and Pam took/take a critical auto/biographic/approach to our embodied materializations working within feministcritical-Indigenous ways of being and knowing. Matt works within critical-feminist frameworks to understand and address cyberviolence through verbatim participatory filmmaking with young women. At this time, in revisiting our collective work, we take the opportunity to deepen our thinking of fleeting encounters and brick walls as these concepts 
animate/embody literacies with/in our everyday relations. Each of us animate particular questions put forward in the call for papers, and briefly articulated below. Our format is once again intended to be conversational with ourselves, and with readers-viewers as we consider the provocations inherent in these questions. Perhaps, you will notice intersections across the questions that provoked us, especially those relating to the collapsing of longstanding Eurocentric ways of being, knowing, and acting, what Marie Battiste (2013) refers to as "cognitive imperialism" currently undergoing significant epistemic and ontological implosion.

Rachael is provoked by historical stories of literate bodies that continue to circulate. She takes us into her everyday life to consider creative/alternative ways of knowing and making- meaning that embodied literacies can open up and/or renew. Katelyn also is provoked by historical stories of literate bodies that continue to circulate, and how a multiplicity of meanings animate intimate moments of lived lives. $\underline{\text { Pam }}$ is thinking/feeling with the intensity of affect experienced with particular pedagogical processes in the context of residential schooling narratives, and the agentic capacity of these narratives to rupture historical grand narratives. And $\underline{\text { Matt }}$ takes us into a collaborative project that opens possibilities and complexities of using verbatim participatory filmmaking with youth to address issues of cyberviolence in the lives of young women and girls in New Brunswick. In order to identify, understand, and resist social, discursive, and institutional issues and brick walls, he is particularly interested in exposing and disrupting paternalistic discursive practices that insidiously make their presence felt when young filmmakers engage with texts, ideas, and other bodies.

\section{Rachael}

\section{Shared Story, Shared Embodiment Through Online Encounters}

I come from Miramichi, New Brunswick. I have been told that the word Miramichi comes from the Mi'kmaq for "river with a varied and plentiful bounty". The city of Miramichi encompasses a small section of that river, and is found just downriver of two Mi'kmaq reserves, and upriver from a third. In the middle lies my city, where a jumble of communities with distinct Irish, Scottish, Francophone, Catholic, and Protestant identities were amalgamated into one city 22 years ago. For most of my life, the area has been in economic decline, and the people of the city have worked together and against one another in an attempt to maintain the lives they built there, all without acknowledgement of the unceded lands on which they and their ancestors built their lives and thrived for many years before this particular downturn. The Miramichi River lies within unsurrendered Mi'kmaq territory, and my people settled on it only 200 years ago.

I recently returned to live on the river, after eight intermittent years of postsecondary education. I sit often in a new coffee shop, in a building that was a 19th century bank, a meeting space, a bowling alley, and now repurposed into something so of-themoment on top of decades of history and stories. I can feel those stories in the building as I try to focus on my graduate work. They are stories of the settlers who came here, took land that did not belong to them, worked hard to clear away trees and build roads, and eventually gained enough stability and capital to build a bank out of red bricks made from the mud of the river. Their morals exhorted them to civilize this place, to impose order, to build square buildings on straight roads along a river that twists and widens, ebbs and rolls, provides life in its movement and its offerings, and kills and destroys without warning. The 
stories of these settlers that echo through this building are my own stories, and I layer on top of their ethic of duty, civic pride, and progress the acknowledgement that my ability to sit here and type on a laptop and think about colonialism and feminism and emancipatory education is thanks to the oppression they enacted on the local Mi'kmaq communities.

My awareness of these layers of meaning has grown over the years since I left the river at 18. I cannot locate my learning of these critical literacies of race, class, gender, sexuality, and histories to a particular course I took, book I read, conversation I had, or tumblr thread I browsed. But I know that I embody them thanks to the Internet. Although for most of my life I lacked awareness of it, Miramichi's working class culture perpetuated a hegemony of White masculinity. People are valued for how hard they work, and hard work only qualifies if it is physical in nature. Working at the mill, hauling timber through the woods, welding in the shop. These trades were the backbone of our economy, and their doors were closed to women. To want to sit and read, then, and not to go outside to pile wood or shovel snow, was seen as lazy and gratuitous. Texts-whether books, movies, or otherwise - existed purely for enjoyment. A level of shame pervaded my body for reading, for doing well in school, and for turning to the Internet to find my way around the brick walls that my community created. There, I sought disruption, and there, with millions of other women and girls, I found it. Together, we fangirled over our favourite books, created transformative works of art, and raged against publishers, television writers, and film directors for failing to represent the diversity we could see in our online communities, in our real lives.

Jessalyn Keller and danah boyd as well as many others have written about girls and the Internet - the ways they use it to mediate their identities, to control their own narratives, to become activists (Keller, 2015; 2012: boyd 2014). Through social media, they narrate their identities and foster conversation and activism. But the Internet also offers a space for the fleeting encounters with the individual actors that Sara Ahmed wrote about; although community and long-lasting relationships develop and exist, fleeting encounters are much more common and can be embodied in lasting ways. Popular discourse would have us believe that the Internet is a place of barriers and abuse - and it is true that the exclusions and violences of offline spaces are often reproduced there-but, it is my intention to focus here on the overlooked positive discourse. The conversations and community that happen among women and girls on the Internet gave me something I could not find elsewhere in my life, and this is something it offers to many. I maneuvered around my brick wall by finding these communities, but my avoidance of the brick wall did not cause it to disappear - just as the systems of oppression at work in our world do not disappear online. Ahmed wrote that "in reflecting on what exists, it withdraws from an immersion, such that an existence is transformed" (2012, p. 174). I would theorize that by creating online communities separate from their lived experiences, women construct the opportunity to leave behind certain embodiments and can reflect on the ways the world acts on them and they interact with the world. They are given the opportunity in these spaces to actively reflect on their experiences without the ongoing negotiations with the brick walls that exist in physical spaces. Whether on their personal blog or in spaces like Rookie Magazine, dedicated to producing content by and for adolescent girls, women have the opportunity to put their thoughts together in their own time, to shape them, to make them look the way they want, free from the constraints of academic expectations, of peer review, of formatting requirements, or even the expectation of a coherent narrative. 
An example that brings this into sharp relief comes to mind: in Rookie, Mariam Ansar writes about an experience she had as a high school student in her classroom, when a boy made a sexist joke that she did not find funny (2017). She raised her voice to speak against him, which only drew the mocking of her peers. Mariam needed the support of her teacher in that moment, but she did not receive it. In public spaces, including school spaces, we can often be confronted by unexpected resistance and as teachers and as critical thinkers, we can let ourselves down in how we react to these moments. The moment solidified for her that despite her tears in the wake of this moment, she would continue to speak up in defence of her fellow women, fellow Muslims, and fellow people of colour.

This was a fleeting encounter that Mariam embodied immediately. It was also a generative encounter. In writing about her experience, Mariam was able to take back control of her narrative - although she could not change the reaction of her classroom peers or of her teachers in her physical environment, she could bring the reader through her feelings as those events happened and demonstrate their affect. Mariam's ability to write about this moment generates more fleeting encounters. Those for people like myself, who have a responsibility to understand the need for allyship and for supporting people who are chipping away at the brick wall. Such stories are important for people who face brick walls similar to the ones that Mariam faces, empowering them in the knowledge that speaking up is difficult and not always worth it in the moment, but can generate the drive to do it again. And for Mariam, although she was not validated in the moment of her resistance by anyone in the room with her, she can have the fleeting encounters offered by commenters on her piece-those who take a moment just to hear her story, and accept it. No one attempts to soften her narrative, no one tries to make excuses.

Although I sit in a coffee shop, far away from where Mariam experienced and shared this encounter, I now encounter her story. I now carry an awareness of her experience and of the ways that such experiences can be encountered, disrupted, and acted upon. Mariam's reflection, like the stories of so many women we can now encounter online, gives us new literacies for encountering our own lives and for looking at the lives around us, allowing us to continue to open ourselves up to new stories and to give us the courage and power to face our brick walls.

\section{Katelyn}

\section{Embodying Educational Literacies Like a Good Squaw}

My perspective is the result of an accumulation of experiences as a Mi'kmaw and English woman within our education system. I continue this conversation by sharing with you now a few of the ways I have come to know myself as embodying brick wall ideologies that have made it difficult, at best, to find space for myself in the many levels of Canada's academic world. I was really taken with the questions: what historical stories of literate bodies, or what it means to be literate, continue to circulate? and how do a multiplicity of meanings animate intimate moments of lived lives? I am particularly interested in exploring these two questions in relation to my experience of participating in Canada's public school system as an Indigenous female living and learning in Mi'kma'ki. The literacies I've come to embody are the unforeseen and long-lasting consequences of my education, and have reared themselves in some of the most intimate realms of my life. 
Encouraging elementary school embodiments. I attended Shubenacadie Elementary School, in which every student took the Mi'kmaw Studies class offered. I remember learning traditional stories, how to weave baskets, simple beadwork, and basic language skills for things such as numbers, animals, and short phrases. We spent hours playing the traditional game Waltes. Within the walls of this classroom I was given my first opportunity to hit the hide of a drum. This class was made possible by two female Elders from my community, Becky Julian and Mary Bernard, and every student participated, not just those from the reserve. To these two women, my learning spirit has an endless amount of gratitude, as these are the educators responsible for my resiliency in knowing that Indigenous knowledges deserve their own respective and respected spaces in our publicschool systems. However, there have been other experiences that contradict the embodied respect I initially was taught in elementary school, and it is those experiences, I now realize, I've embodied deeply.

Racist math jokes and safer spaces—high school is a weird place. We are going to fast forward to high school, as there was zero academic Indigenous content throughout my middle schooling. I attended Hants East Rural High School (HERH), which was the closest high school to the reserve, so there has always been a high concentration of Mi'kmaq students contributing to the student body population (my father, aunt, and grandfather also attended this school). There were (and are still are) no Mi'kmaq teachers; we had a Mi'kmaq guidance counselor, my uncle, who holds the position to this day. He is a great support for our students, but at the end of the day, he is there to listen to the students, offering guidance and support from his office; he is not in the classrooms where a lot of damaging actions and ideologies are represented, dismissed, and/or left to fester, leading to harmful embodiments by students, Indigenous and otherwise.

In high school, there was one course with Indigenous content titled Native Studies 10. It was an elective, not recommended, and most of the students were from my community, Sipekne'katik. The teacher who taught the course while I attended HERH was not an Indigenous educator but an African Canadian man who admitted, often, that he did not know first-hand what he was teaching, but he was most certainly better than nothing at all. As a Black man in Nova Scotia, he had experienced systemic racism and the oppression of being a minority, which was comforting to those of us from Sipekne'katik who took the class. The memories I have of this class were that these were the first discussions I had in an academic setting about institutional racism, although that was not the language we used in our classroom; at the time, it just seemed like a safe academic space for us to share our experiences and frustrations about continually coming up against this unwelcoming and unmovable force (what we refer to in this paper as a "brick wall"). This was the first experience I had of a class being personally validating, while also opening my eyes to the magic that can be created when Indigenous students share their experiences in a respecting space.

What do Indians like on their toast? Have you ever done one of those math worksheets where you have to solve a bunch of math equations and every answer matches with a letter, so at the end of the worksheet once you've answered all the questions, you get the answer to a joke or a riddle? One afternoon in my $10^{\text {th }}$ grade math class, my teacher handed out one of these worksheets; the headline question we were solving for read, "What 
do Indians like on their toast?" Annoyed, but admittedly curious as to what the answer could possibly be, I said nothing and completed my worksheet. Upon solving the final math problem and having the answer "Squaw-berry jam" wrenching at my insides, I approached my math teacher to express my shy but grounded concern over the racist content of the worksheet she had handed out and instructed everyone to complete. To my literal horror, she told me that it was "just a joke," that I was taking it too seriously, upsetting myself over nothing, and should to return to my seat.

For what felt like months afterwards, I was made fun of for "not being able to take a joke" and heard this racist incursion directed at me countless times. Was I a squaw? When you hear something enough times, it starts to sink itself into you. Just like Mariam Ansar (2017) in Rachael's telling, I too embodied my teachers' dismissal immediately. What makes experiences like this so terrifying is that the students who are continually receiving discriminatory ideologies are not likely to question what they are receiving because the discrimination is framed as "just a joke". Unfortunately for me, I internalized that it was acceptable for my ancestry, specifically the strong and resilient women of my ancestry, to be the butt of academic jokes, and that this was not offensive, but funny. As a member of that dismissible group, my voice did not stand a chance of being valued in that world. This is the voice I speak with still today.

I would like to take a moment here to speak with you about what I feel is a clear example of what a multiplicity of meanings animating intimate moments is like for me in this situation. I do not wish to explicitly state that my 10th Grade math teacher created this racist and sexist worksheet because she is racist and sexist; I do not think she created it, and she probably didn't consider herself to be racist. I have often wondered how she feels about this encounter with me; if she feels she did the right thing by dismissing me and my concerns back to my desk. I wonder if this fleeting encounter still resonates with her, or if this was just another class for her, a fleeting unremembered encounter which blurs into all of the other forgotten classes she has taught. This is where I feel embodiment is easily transferred-in spaces we've forgotten about. She embodied the ideology behind the squaw-berry jam worksheet, and, given her potential influence as a teacher, I'm sure I'm not the only student of hers who learned to embody this discriminatory ideology.

Denial of (academic) existence: undergraduate lies. Let me now take you to the final semester of the four years I spent at Saint Mary's University in Halifax, Nova Scotia. At the time, I was an honours student majoring in Philosophy and minoring in Theology and Religious Studies. If there were any mentions of Indigenous content previous to this, I do not remember them. What I do remember, however, took place within my two final courses: Bioethics, and Feminist Philosophy. As my final assignment within the Feminist Philosophy course, I was surveying fellow philosophy students on what changes they would like to see within the Philosophy department. While I was handing out my short five-question survey in the Bioethics course I was enrolled in, a fellow student asked me what I would like to see change within the Philosophy department, one of the questions I was asking on my survey. The inclusion of female philosophers and Indigenous philosophies was my answer, to which the professor responded that there was no such thing as Indigenous philosophies, nor any female philosophers. While I could provide names of famous female philosophers to counter his claim, I am ashamed to admit that I was unaware of any Indigenous philosphers/philosophies at the time, which must have only reinforced 
his claim amongst my fellow students. I won't even begin to discuss how many times he interrupted me and spoke over me while I was giving the preamble for my survey.

Fast forward again to the beginning of my graduate studies in the department of Education at the University of New Brunswick. While I now have the absolute joy of reading the incredible work of many Indigenous scholars', I continue to find myself facing and embodying institutional racism. The racism in this setting is not overtly noticeable; it's not like I have been called a "squaw" in this department. Rather, it is all the little things that accumulate and grind a person down. I had written a paper on the concept of neocolonialism last year for a course, and set up a meeting with the professor to go over my paper. The first problem I can remember him having with my paper was that I had misspelled "Wabanaki": he told me that I had spelled it "Abenaki" accidently. When I voiced to him that I had not misspelled but was referring to the Abenaki people, who are one of the five contributors within the Wabanaki Confederacy, he responded with "oh."

This may not seem like a big deal to anyone else besides me, and it has taken hours of thinking obsessively to be okay with that; it can matter to only me, but that means that it still matters. This is an example of a position of authority in a Eurocentric institution assuming that he knew what he was talking about when it came to Indigenous knowledges, and dismissing me when I had corrected him. So, once again, it was assumed that a privileged male who had good authority in the institution knew more about Indigenous history than an Indigenous woman. This was the final strike that engulfed my deeply rooted pain into the swirling ball of rage and humiliation it is today.

Embodied literacies and affectivelaffected work. So here I am today-feelings of anger and shame permeate my thoughts while I am still trying to figure out how to recreate the magic I experienced in elementary school despite those fleeting academic encounters that have taught me this is not where I belong. Experiences like those shared above have been accumulating within me for the 18 or so years I've been a participant in the world of institutional education and it has left me scarred and, at times, academically and internally paralyzed. I am swollen and bitter at the learned literacies I embody against myself unknowingly yet so deeply. I don't speak in class because I embody the dismissal my education and its delivery-boys have taught me. I am afraid that nobody will hear me, and if they do, they won't actually be listening - all they will hear is my anger and I will only perpetuate the stereotype of an angry Indian, another uneducated squaw. I am ashamed that this is who I have become. I never used to consider myself to be an angry person.

But anger is part of my healing journey; I am grieving the loss of the proud Mi'kmaq woman I could have been my entire life. I am grieving the cultural loss of the children taken from their families and communities and restrained/contained/maintained in residential schools and day schools, or placed with families other than their own. I grieve for the thousands of women, girls, and 2-spirited Peoples murdered, hundreds of whom remain missing. I am grieving for the Earth: for the land, air, and waterways we continue to molest through resource extraction. I grieve for all of our losses of life.

I am ultimately afraid that my colonized education is right - that my voice, my experiences are dismissible in this world and I just need to learn to accept that, to learn how to take the joke, how to be the joke. It is in having difficult, yet ongoing, conversations like this one and co-creating spaces for these conversations to be had, online and in person, that helps me to realize that sharing these experiences of embodiment allow others to 
challenge the daily little things that go unnoticed and wreak havoc internally. The next time you hear someone make a discriminatory joke or remark, I'm hoping that you won't let it slide after taking part in this ongoing conversation.

Leanne Betasamosake Simpson (2011) brilliantly places "shame as an insidious and infectious part of the cognitive imperialism that was aimed at convincing us that we were a weak and defeated people, and that there was no point in resisting or resurging" (p. 11). These memories I'm sharing with you are the beginning literacies of my own resistance and resurgence as an Indigenous woman. It is the accumulation of singular voices that slowly chip away at towering brick walls; I am hopeful that perhaps these memories I've shared with you will contribute, however minimally, to the recognition, and inevitable crumbling demise of these epistemically assimilative and internally damaging brick walls.

\section{A Fleeting Changing Encounter with Isabelle Knockwood: Uncovering Lies of Omission as a Way to Embody Truths-Telling}

Pam

I live and work on the unpurchased and unceded territory of the Wolastəkwewiyik peoples. My settler family, on my father's side came to live in New Brunswick from Wexford, Ireland in the early 1800's and, on my mother's side from Banffshire, Scotland in the late 1800's. Our family has benefited greatly from the Peace and Friendship Treaties. In my life as an inhabitant of what is now called New Brunswick, and as a faculty member of the University of New Brunswick, and in the broader community, I strive to work in the present towards a time when First Nations rights are upheld with the same tenacity as the rights of settlers. In this part of our ongoing conversations, I speak to residential schooling narratives, affect, and epistemological shuddering as a way to crack open ourselves and omissive curriculum that tells only part of our Canadian-Turtle Island story, and in so doing keeps us from each other.

Katelyn's home of Sipekne'katik, is very close to the former location of the residential school at Shubenacadie. It was Isabelle Knockwood, from Katelyn's community, who introduced me to Out of the Depths: The Experiences of Mi'kmaw children at the Indian Residential School at Shubenacadie, Nova Scotia. Knockwood published this book in 1992, and was visiting the UNB Mi'kmaq-Wolustoqey Centre for a reading and signing in 1994 when I had the opportunity to meet her. As she signed her book with the words "Let the healing begin," I was struck by her generosity, knowledge, and matter-of-fact approach - that Indigenous and non-Indigenous peoples alike needed to be working together to discuss what really happened in these residential schools: brick buildings that closed off Indigenous children to themselves and their families-literal brick walls creating longstanding cultural divides between Indigenous and non-Indigenous peoples. "There is a lot of healing that needs to take place" is what she said-unsettling my white guilt, and calling for me to act. What I took away from my fleeting encounter with Isabelle Knockwood was the need to learn more about and circulate other truths about Canada-Turtle Island, to make visible the injustices and harms of residential schooling policy, practices, and its intergenerational effects. I see truth-telling as a way to epistemic inclusion while dismantling bricked-up discourses. Out of the Depths is a deeply disturbing narration of the firsthand experiences of 27 adults who had been forced, as children, to leave their families and live at Shubenacadie Residential School (1930-1967), the only full- 
time residential school in the Maritimes - a residential school that was home to 1000 children during its 37 years.

In his report to Indian Affairs on education for Indigenous children, the highly influential Egerton Ryerson, (1847) put it this way: "Their education must consist not merely of the training of the mind but of a weaning from the habits and feelings of their ancestors, and the acquirements of the language, arts and customs of civilized life" (Ryerson, as cited in Alexander, 2010, p. 133). Within her collection of autobiographical narratives Knockwood cracked open "the code of silence" (p. 11), making public what it meant for a national policy that called for young children to be "weaned" from their ancestors and "acquire" customs of what was clearly, for many, a life of abuse, one that created intergenerational trauma for generations to come. Within her re-constructed conversations, Knockwood details the everyday lives of children taken from their families to be raised by the so-called "brothers, sisters and fathers" of this Roman Catholic school/home. Quite literally stripped of their language and culture, - - the children narrated by Knockwood articulate the shaming of Mi'kmaq bodies, hearts, and minds. The imposed taking on of English Catholic trappings in what was the home, school, and, all too often workplace of Mi'kmaq children, made palpable the domestic violence, harassment, abuse and neglect that took place within the school—which we must remember was the children's new home. More than educators, these nuns and priests were fathers and mothers.

Prior to 1876, attendance at residential schools was voluntary. However, an amendment to the Indian Act of 1876 required that Indigenous children attend residential and day schools administered by churches; a government of Canada policy enacted by priests and nuns. By 1900, within their newly designated homes and with their forcibly designated families, Indigenous children were dying in large numbers. In 1907, with the Federal investigations of Indigenous Industrial Schools in Manitoba, Saskatchewan, and Alberta, Dr. Peter Bryce, Chief Medical Officer for the Department of Indian Affairs of Canada found high rates of death from tuberculosis. His findings received publicity within the Canadian press, and dismissiveness from the Canadian government. Duncan Campbell Scott, Minister of Indian Affairs, in his response to Bryce's reports was unequivocal:

Even were the Department prepared to take the schools over from the Churches, it is self-evident that the Churches would not be willing to give up their share of the joint control. These preliminary examinations by Dr. Lafferty and Dr. Bryce have already caused considerable irritation and brought protests from the Roman Catholic authorities who have the larger number of pupils under their charge. (First Nations Education Steering Committee \& First Nations Schools Association, 2015, p.17)

If the Bryce report had been taken more seriously, perhaps the Shubenacadie School (19301967) might never have opened. Perhaps many other brick-walled schools might not have been built. Perhaps many Indigenous families, their cultures and languages may have been left intact. Instead, the government of Canada chose the literal brick walls of the residential schools as the homes for 150,000 children-leaving many families and communities bereft of children - and children bereft of their families, languages, and culture for generations to come. These literal and ideological walls are now tumbling down as more and more 
residential narratives have been revealed through the Truth and Reconciliation Commission (2015).

A brick wall within: Epistemic shuddering. In 1995, I placed Out of the Depths as an optional reading for the Cultural Constructions of Childhood course I taught, my pedagogical intent being to introduce the histories residential schools to expose the narrowness of colonial narratives by circulating other truths. These narrative truths detailed children and childhoods dislocated, damaged, and destroyed through removal from homes, families and land, from original and longstanding traditional literacies embedded and embodied in the lands where the Mi'kmaq peoples have lived for at least 12,000 years. This home within the child was eviscerated in a generation.

There were 24 people in the Cultural Constructions class. I offered the book as one of a number of options, rather than as a mandatory assignment. The class members who chose to read Out of the Depths were five First Nations people, already familiar with residential school narratives circulating in their families and communities-people carrying deeply embodied intergenerational effects and narratives. The settler participants in our class chose to read other materials; not familiar with residential schooling, perhaps, it appeared they thought this book was not for them. They embodied other literacies, other stories-official grand narratives that disappeared Indigenous people-made them historic. And so, we remained apart: Indigenous peoples carrying a fuller picture of Canada, and settlers re-inscribing grand narratives while remaining oblivious to, and apparently uninterested in, other people's truths.

I remember being stunned. My insides came crashing down, an effect of running into my own brick wall. My quickly crumbling interior construction created a massive epistemological shudder (MacNaughton, 2005), perhaps an epistemic earthquake as I encountered the affective manifestation of a pedagogy of choice. Sara Ahmed (2012) writes that the "research process is a process of estrangement which creates an orientation in which some things come into view that had been previously obscured" (p. 10). In this case, my pedagogic intentions revealed the deep cultural, linguistic, and racist chasm existing between the epistemologies of Indigenous and non-Indigenous people - the absent truths of Indigenous stories and experiences, and the half-truths of deeply embodied Eurocentric schooling.

Encountering my teaching settler treaty self: Truth-telling and Indigenous storying. Now 22 years later in my $27^{\text {th }}$ year of teaching and learning at UNB post Royal Commission of Aboriginal Peoples (1996) and currently within the time of the Truth and Reconciliation Commission (2015) and movments such as Idle No More (see www.idlenomore.ca), most people coming into university classes in the Faculty of Education are very aware of residential schooling. Still, each year there are one or two people who don't know and are surprised, angered, shamed, outraged, and galvanized into action when they learn of what happened to innocent children, and to Canada, as a consequence of deliberate government policy to make Indigenous culture, language, and actual bodies disappear. In my childhood and too long into my adulthood, as I have written about elsewhere (Whitty, 2017), Indigenous people, languages and cultures were disappeared for me (Tuck \& Yang, 2012, p. 6). I was/am one of many settlers who lived and learned what Daniel Francis referred to as the "image of the Indian, the "Imaginary Indian" (1992, p. 5), the one invented by Christopher Columbus upon his arrival to the Americas where he collectively named the 
diverse First Peoples living here as one. My family who settled on traditional unceded Mi'kmaq land in northern New Brunswick, over 200 years ago, have incurred immense one-sided benefits as Treaty people (2007). And I am just beginning to learn what it means to be a Treaty person (Johnson, 2007) on these unceded Wolustoqey territory where I make my home.

Rachel Bryant (2017) in The Homing Place: Indigenous and Settler Literacy Legacies of the Atlantic powerfully explains how "colonized and Indigenous environments occupy the same given geographical coordinates even while existing in distinct epistemological worlds." In her work, she calls for settlers like herself, and many of us, to listen to stories that Indigenous peoples have been telling for centuries. She writes: "As a nation, we need fundamental change in all levels of Canadian society and culture because Indigenous peoples, histories and modes of thought have never been just another thing we could absorb or assimilate into our fort" (p. 185). In bringing this conversational thread to a close, I encourage each of us to continue to unsettle and transform y/our embodied storied selves. Animate y/our everyday lives and literacies: read, read, read; view, view, view; listen, listen, listen; talk, talk, talk, and bring the continuing power of Indigenous storying to y/our lives. Find stories by Richard Wagemese, Kathleen Vermette (2017), Julie Flett (2017), David Robertson, Leanne Betasamoke Simpson (2017) — to name just a few —and invite them into y/our everyday lives, teaching, research, citations, service, families and friends as one way to continue to unsettle y/ourselves. Welcoming these stories is one way to take up the calls to action articulated in the Truth and Reconciliation Report, to continuously crack open Knockwood's code of silence, and to listen to and learn many truths. And maybe you would like to try out Raven Reads - an idea enacted by Nicole McLaren making reading her way, and I possibly y/ours, to truth and reconciliation (https://ravenreads.org). You can listen to her just here on Unreserved hosted by Rosanna Deerchild - https://www.cbc.ca/listen/shows/unreserved/segment/14948640

\section{Addressing Issues of Cyberviolence in the Lives of Young Women and Girls Through Verbatim Participatory Video Dramas}

Matt

In 2014, Status of Women Canada (SWC) initiated a nationwide proposal-based funding program entitled Cyber and Sexual Violence: Helping Communities Respond. The program invited regional stakeholders to submit applications for research projects that explore the prevalence of, and ways to address, cyberviolence in the lives of young women across Canada. In 2016, I was invited to be a part of the dissemination phase of one of these projects in New Brunswick. The knowledge-building phase of the research comprised a province-wide series of interviews and focus groups with young identifying women. I was to take the information gathered from the earlier phase of the research and work with a different group of young women. These new participants were invited to produce a participatory video drama, that draws on a verbatim cinema approach, based on themes in the earlier research. Our intention was to mobilize the voices of young women from earlier phases of the research for other youth and to use an arts-based approach to accent youth agency and address institutionalized paternalism. As identified in earlier phases of the study, young women found that paternalistic approaches informed and limited responses to cyberviolence in schools and communities. Although these two goals guide our work, 
our team of young New Brunswick filmmakers have run up against discursive brick walls that place limitations around the project.

For this provocation, I draw attention to how paternalistic discourses have influenced the way audiences understand our work. I question whether our approach, chosen to embolden youth agency, has helped us move beyond paternalistic institutional discourses. I ask whether our approach has encouraged audiences to engage with young women's voices, or whether paternalistic discourses continue to cause audiences to overlook young people's political expressions. Below I outline the participatory video drama and verbatim cinema methods the young women and I adopt for the dissemination phase of the research. To provide more richness and depth to this discussion, I also include a short behind-the-scenes documentary that accents some of the young women filmmakers' perspectives on the project and their goals. Then I elaborate on some discursive tensions we have been experiencing when presenting the work. I conclude with a few questions to provoke reflection. I do this so we might encourage a more meaningful engagement with the participatory visual works in the project, and the young women's voices it helps express. I begin, however, by providing more context and elaboration about the New Brunswick iteration of the cyberviolence project.

In 2014 the Muriel McQueen Centre for Family Violence Research, the New Brunswick Social Workers Association, and the New Brunswick Office of the Child and Youth Advocate proposed a project that fit within the mandate of the national SWC program titled "Project to Prevent and Eliminate Cyberviolence against Young Women and Girls in New Brunswick."As described in one report (Muriel McQueen Fergusson Centre, 2017a), their work seeks to contribute to knowledge and policy change at government, policy, educational, and institutional levels. Through interviews, surveys, and focus groups across the province, the research team worked with young identifying women between the ages of 16 and 19. Interviews with the young women focused on institutional responses to cyberviolence and the lived experiences of cyberviolence in New Brunswick. Emerging themes in the research included gendered experiences of cyberviolence, the complicit role of social media platforms that encourage anonymous publication, and the implications of permanency in relation to social media (Muriel McQueen Fergusson Centre, 2017b).

The participants also raised an important criticism that troubled the research partners: most approaches to dealing with cyberviolence adopted by schools, serviceproviders, public institutions, the media, lawmakers, and researchers are limiting, alienating, and marginalizing for young women. Some participants suggested that a generational power dynamic means that adults, professionals, and law enforcement agencies always seem to have ownership over the narrative of, and initiatives intended to address, cyberviolence (Muriel McQueen Fergusson Centre, 2017b). When cyberviolence is addressed in their schools or in the media, some saw the topic located in talk that is blaming, sexist, or discussed in a restrictive or punitive way for youth. These power dynamics became clear in comments made by one young woman when she discussed how schools deal with cases of sexual exploitation (e.g., when intimate partner photos or 'sexts' are shared or transmitted over social media). As she put it: 
When the school hears about nudes going around they freak out. But what you don't realize is the girl is probably freaking out enough about the fact that her nudes are going around without a lecture on how it's child porn (Participant Interview).

Her comment shows that young women are not only navigating sexual violence but also deal with victim-blaming discourses and institutional paternalism when schools try to address sexual exploitation. The comment also highlights how young women are often disregarded in efforts to shape knowledge and/or address issues of cyberviolence. The young woman's criticism illustrates Sara Ahmed's (2012) notions of institutional brick walls. Here, a brick wall limits young people's involvement in addressing an issue that impacts their lives. This wall is generational, gendered, and connected to dominant paternalistic discourse about youth and the need for their protection. Whereas the notion of a responsibility for adults to protect youth from harm might be something difficult to question, the initial work with young women in New Brunswick revealed how uncritical paternalistic approaches can limit discussions, be alienating, and can further marginalize young women who may already deal with serious issues.

For the New Brunswick research partners, the prevalence of paternalistic approaches to dealing with cyberviolence accented a problem in their project's design. The team questioned whether young women had been genuinely represented in their research efforts to explore and address cyberviolence at an institutional level. This stirred them to reflect on how their knowledge- building pursuits might be influenced by paternalism, or how their recommendations might also contribute to marginalizing power relations for youth and young women. Their reflections encouraged them to pursue more participatory ways to disseminate research findings to and with youth. The partners then recognized the need for young people to be involved, as key stakeholders and as meaning-makers, in the conversation about the research going forward.

In 2016, the research team invited me to be a part of the dissemination phase of the project. I proposed sharing research findings through participatory visual methods in a collaborative media project with a new group of young women from the province. We pursued a participatory narrative filmmaking distribution strategy that involves young women writing, directing, and producing a fictional film that represents, sometimes in a verbatim fashion, elements of the broader research data. The project draws inspiration from a combination of participatory video drama (Brickell, 2015; Milne, Mitchell, \& de Lange, 2012; Mitchell, 2011; Shaw, 2016; Walsh, 2016) and verbatim theatre/cinema (Mienczakowski, 1995; Shah \& Greer, 2017; Uzun, 2017). Participatory filmmaking methods involve grassroots groups or community members in knowledge-building and sharing activities through collaborative media projects. Whereas a good deal of participatory video projects find inspiration in documentary filmmaking methods, participatory video dramas as Waite and Conn (2011) explain, signifies participatory filmmaking that incorporates fictionalized narratives as part of the story-telling. The research team and I invited the new group of young women who to produce a narrative film that interprets, responds, and reflects on the voices of young women from the earlier components of the research. This extension of participatory video drama methods is inspired by notions of verbatim theatre/cinema. Verbatim approaches involve dramatized recreations of research texts (Abdullah \& Khalaf, 2016). For Mitchell, de Lange, and Moletsane (2017), participatory visual methods and filmmaking can provide unique 
possibilities for community-based meaning-making that can encourage more fair societal practices and decisions/policy-making at an institutional level. However, as the young filmmakers and I now understand, the same paternalistic institutional discourses identified by the young women in the earlier phases of the study impact how audiences respond to our verbatim participatory video narrative approach, as will be developed more below.

In January 2017, after some combined recruitment efforts with a teacher in a local secondary school, eight young identifying women volunteered to be a part of the participatory verbatim filmmaking project. Since that time, the group has been engaging and interacting with texts from the earlier parts of the research project. Through their encounters with each other, and with these texts, they are working towards a cinematic narrative that will act as an accessible vehicle to mobilize the research findings and engage with people who might not have opportunities to interact with traditional academic research. Through a verbatim approach, the group is adding another representational layer to the study (i.e. actors' portrayals, and narrative fictionalized representation of the research findings). They have used specific quotes from interviews of earlier phases of the research as lines of dialogue and narration in their larger fictional narrative. Once complete, the work will be accessible to other youth - in school contexts, teacher education, teacher professional development, academic conferences, regional film festivals, and film festivals designed for youth. The New Brunswick research partners also intend to integrate the film into a toolkit for educators and service providers (Muriel McQueen Fergusson Centre, 2017b). Participation within the film group is on a volunteer basis, and participant numbers since January 2017 have varied based on school and life circumstances. In March 2018, with the help of the New Brunswick film community and the New Brunswick filmmakers' co-op, the young filmmakers completed the principal photography for their short film, Social Proof. Group meetings are ongoing and three of the filmmakers are editing the film.

In this short behind-the-scenes documentary below, the young filmmakers summarize how they have been engaging with research texts and making new meaning through their collaborations. As raised in the documentary, some young women saw their involvement as a way to "blow this research up."

Video Link https://www.youtube.com/watch?v=ikOt2w1cshQ\&feature=youtu.be

Over the last few months, the young filmmakers have had a few opportunities to share the documentary and their emerging work with community partners and the public. In debriefing sessions after these discussions, the young women have expressed that powerful paternalistic discourses are still influencing how adults, educators, and service providers are responding to discussions about cyberviolence, youth, and their work. For example, after presenting the project at a public meeting with adults who work in crime prevention, education, and other initiatives to address cyberviolence, one of the young filmmakers expressed how the audience might have only engaged with their voices in hallow, inconsequential, and almost patronizing ways. She explained how the audience only engaged with her, and the other filmmakers, at a superficial and congratulatory level. Within minutes of their presentation, which focused on the need for supporting youth agency in addressing cyberviolence, discussions in the room reverted to ideas influenced by paternalistic discourses. Our most pressing concern with these responses to the project is they leave discursive brick walls of institutionalized paternalism intact. I am interested 
in addressing these discourses in the moment, when they surface around the dissemination film project.

Recently, three of the young filmmakers and I presented the project to a group of academics at the University of New Brunswick in a Work in Progress speaker series in the Faculty of Education. As a response to the experience the young women have had when presenting this work, and in an effort to find solutions, we fashioned a panel presentation and facilitated a brainstorming session. We tried to engage the audience in discussions about the problematic and dismissive elements of paternalistic discourses. We also brainstormed several ideas about how we might resist, challenge, and subvert these discourses when they come up. We considered how the film that the young filmmakers produce, and texts around that film, might also contribute to disrupting those discourses. The conversations were productive, and, most likely because we addressed the paternalistic discourses head-on, responses from the audiences differed from before.

Within this project, we will continue to negotiate how we frame discussions about the film project. We will also continue to think about how we might encourage audiences to reflect on the themes and political messages the filmmakers present in the film. I intend to keep the following questions at the forefront of my thinking when collaborating with the filmmakers and the research partners: How might we, as researchers and collaborators involved in the project, find some productive ways to resist or disrupt paternalistic discourses when they circulate around these projects? What inadvertent ways might we be inviting, inducing, or validating paternalistic discourses? And, how can we renegotiate our approaches so that paternalistic discourses aren't enlivened?

\section{In Closing-For Now}

In coming together and sharing our conversational space with you, we hope to have provided mutual inspiration, support, and stories that resonate with ethical responsibilities you may be encountering as a learner and an educator. Given the increasing recognition to act on the epistemic divide between Indigenous ways of knowing and being, and those embedded and embodied with/in cognitive imperialism - as Rachael, Katelyn and Pam have expressed-alongside the constant need to subvert paternalistic discourses in our everyday conversations - as Matt's work has shown-we would like to close the paper with questions from Daniel Heath Justice, a Colorado-born Canadian citizen of the Cherokee Nation. In Why Indigenous Literatures Matter (2017), Justice speaks to the "the many kinds of stories Indigenous peoples tell, and the stories told about them, stories that can "strengthen, wound or utterly erase our sense of humanity and connections" (p. xvii). He suggests four questions to be considered as processes to guide Indigenous peoples to speak to, understand, and share their diversities. These questions can also point to ethical ways of being for all humans as we engage with each other in processes of teaching, learning and research. Justice suggests:

How do we learn to be human?

How do we behave as good relatives?

How do become good ancestors?

How do we learn to live together? $(2017$, p. 28$)$ 
To continue the conversation, off the page, you may also wish to listen to an interview with Daniel Heath Justice and Rosanna Deerchild on CBC's Unreserved. Thank you for your attentiveness.http://www.cbc.ca/radio/unreserved/how-indigenous-authors-are-claimingspace-in-the-canlit-scene-1.4573996/our-literatures-matter-because-we-do-saysindigenous-author-daniel-heath-justice-1.4577944

\section{References}

Abdullah, A. R., \& Khalaf, A. A. (2016). Truths ethics and politics and their relation to verbatim theater. Journal of Humanities, 17 (4), 258-267.

Ahmed, S. (2012). On being included: Racism and diversity in institutional life. Durham, NC: Duke University Press.

Ahmed, S. (2017). Living a feminist life. Durham, NC: Duke University Press.

Alexander, B. (2008). The globalization of addiction: A study of poverty of the spirit. Oxford: Oxford University Press.

Ansar, M. (2017, May 10). Trusting your own authority. Rookie, 69. Retrieved from http://www.rookiemag.com/2017/05/trusting-your-own-authority/

Battiste, M. (2013). Decolonizing education: nourishing the learning spirit. Vancouver, BC: Purich-UNB Press.

boyd, d. (2014). It's complicated: The social lives of networked teens. New Haven, NY: Yale University Press.

Brickell, K. (2015). Participatory video drama research in transitional Vietnam: postproduction narratives on marriage, parenting and social evils. Gender, Place \& Culture, 22(4), 510-525.

Bryant, R. (2017). The homing place: Indigenous and settler literacy legacies of the Atlantic. Waterloo, ON: Wilfred Laurier Press.

Canada Minister of Supply and Services. (1996). People to people, nation to nation: Highlights from the report of the Royal Commission on Aboriginal Peoples. Ottawa, ON: Royal Commission on Aboriginal Peoples.

Canada Privy Council Office. (1996). Report of the royal commision on Aboriginal peoples. Ottawa, ON: Canada Communication Group Publishing.

Canada Truth and Reconciliation Commission. (2015). Honouring the truth, reconciling for the future. Ottawa, ON: Author.

Canada Status of Women. (2017). Theme: Preventing and eliminating cyberviolence. Retrieved from http://www.swc-cfc.gc.ca/fun-fin/cfp-adp/2013-2/t1-en.html

D'Amico, M., Denov, M., Khan, F., Linds, W., \& Akesson, B. (2016). Research as intervention? Exploring the health and well-being of children and youth facing global adversity through participatory visual methods. Global Public Health, 11(5-6), 528-45.

Deerchild, R. (Interviewer) and Justice, D. H. (Interveiwee). (2017). Unreserved.

Retrieved from CBC Radio One Unreserved website:

http://www.cbc.ca/radio/unreserved/how-indigenous-authors-are-claiming-spacein-the-canlit-scene-1.4573996/our-literatures-matter-because-we-do-saysindigenous-author-daniel-heath-justice-1.4577944

Deerchild, R. (Interviewer) and McLaren, N. (Interviewee). (2017). Unreserved. Retrieved from CBC Radio One Unreserved website: https://www.cbc.ca/listen/shows/unreserved/segment/14948640 
First Nations Education Steering Committee and First Nations Schools Association. (2015) Indian residential schools \& reconciliation teacher resource guide 11/12. Book 2: The documentary evidence. Vancouver, BC: Author.

Flett, J. (2017). When we were alone.Winnipeg, MB: Highwater Press.

Francis, D. (1992). The imaginary Indian.Vancouver, BC: Arsenault University Press.

Johnson, H. (2007). Two families: Treaties and government. Saskatoon, SK: Purich Publishing.

Justice, D. H. (2017). Why Indigenous literatures matter. Waterloo, ON: Wilfred Laurier Press.

Keller, J. (2015). Girl power's last chance? Tavi Gevinson, feminism, and popular media culture. Continuum: Journal of Media \& Cultural Studies, 29(2), 274-285.

Keller, J. (2012). Virtual feminisms. Information, Communication \& Society, 15(3), 429447.

Knockwood, I. (2015). Out of the Depths: The Experiences of Mi'kmaw children at the Indian residential school at Shubenacadie, Nova Scotia. Black Point, NS: Fernwood Publishing.

Low, B., Brushwood Rose, C., Salvio, P., \& Palacios, L. (2012). (Re)framing the scholarship on participatory video: From celebration to critical engagement. In E.J. Milne, C. Mitchell, \& N. de Lange (Eds.), Handbook of participatory video (pp. 49-64). Lanham, MD: Altamira Press.

MacNaughton, G. (2005). Doing Foucault in early childhood education: Applying poststructural ideas. London: Routledge.

Mienczakowski, J. (1995). The theater of ethnography: The reconstruction of ethnography into theater with emancipatory potential. Qualitative Inquiry, 1(3), 360-375.

Milne, E.J., Mitchell, C., \& de Lange, N. (2012). Handbook of participatory video. Lanham, MD: Rowman \& Littlefield Publishers.

Mitchell, C. (2011). Doing visual research. Thousand Oaks, CA: Sage.

Mitchell, C., de Lange, N., \& Moletsane, R. (2017). Participatory visual methodologies: Social change, community and policy. London: Sage Publications.

Muriel McQueen Fergusson Centre. (2017a). Preventing and Eliminating Cyberviolence Against Young Women and Girls in New Brunswick. Retrieved from https://www.unb.ca/fredericton/arts/centres/mmfc/_resources/cyberviolenceonepa gerinformationforwebsite.pdf

Muriel McQueen Fergusson Centre. (2017b). Project to Prevent and Eliminate Cyberviolence against Young Women and Girls in New Brunswick (Focus Group Report). Fredericton, NB: Author.

Robertson, D. (2012). Sugar Falls: A residential school story. Winnipeg, MB: Highwater Press

Rogers, M. (2016). Problematising participatory video with youth in Canada: the intersection of therapeutic, deficit and individualising discourses. Area, 48(4), 427-434.

Shah, S., \& Greer, S. (2017). Polio monologues: Translating ethnographic text into verbatim theatre. Qualitative Research, 18(1), 56-69.

Shaw, J. (2016). Emergent ethics in participatory video: Negotiating the inherent tensions as group processes evolve. Area, 48(4), 419-426. 
Simpson, L. B. (2011). Dancing on our turtle's back: Stories of Nishnaabeg re-creation, resurgence and a new emergence. Winnipeg, MB: ARP Books.

Simpson, L. B. (2017). As we have always done: Indigenous freedom through radical resistance. Minneapolis, MN: University of Minnesota Press.

Tuck, E. \&Yang, K. W. (2012). Decolonization is not a metaphor. Decolonization, Indigeneity, Education and Society 1(1), 1-40.

The Movement. Idle no More. Retreived from: http://www.idlenomore.ca/story

Uzun, F. (2017). "Very Frustrating Mexican Removal" An immersive $360^{\circ}$ verbatim documentary. (Master's thesis). Retrieved from OCAD University Open Research Repository.

Vermette, K. (2016). The break. Toronto, ON: House of Anansi Press.

Wagemese, R. (2012). Indian horse. Madeira Park, BC: Douglas \& McIntyre.

Wagemese, R. (2015). Medicine walk. Toronto, ON: Penguin Random House.

Waite, L., \& Conn, C. (2011). Creating a space for young women's voices: Using 'participatory video drama' in Uganda. Gender, Place \& Culture, 18(1), 115-135.

Walsh, S. (2016). Critiquing the politics of participatory video and the dangerous romance of liberalism. Area, 48(4), 405-411.

Whitty, P. (2017). Complicating literacies: Settler ways of being on Wabanaki territory. In R. Zaihi \& J. Rowsell (Eds.), Literacy Lives in Transcultural Times. In the Expanding Literacies in Education Series(pp.17-31) New York, NY: Routledge.

\section{Author Biographies}

Rachael Bell is a graduate of the Master of Education in Critical Studies program at the University of New Brunswick. She currently lives in Miramichi, New Brunswick on the unceded and unsurrendered territory of the Mi'kmaq people where she works as a grade 6 teacher.

Katelyn Copage is originally from Sipekne'katik, Nova Scotia, and is currently living on unceded and unsurrendered Wolastoqey territory. She is pursuing a Masters of Education in Critical Studies at the University of New Brunswick, which is also situated upon the unpurchased and unceded Wolastoqey lands.

Matt Rogers is an educational researcher and an Atlantic Canadian filmmaker. His research focuses on the intersection of critical pedagogy and participatory filmmaking with youth in school contexts. He is also active in the NB film community. His film work has been internationally recognized with awards and nominations in cinematography, editing, writing, and direction.

Pam Whitty is an educator-researcher at the University of New Brunswick on the unpurchased and unceded territory of Wolastoqey peoples. Her work in early childhood studies, literacies, and curricula is situated within a critical re-conceptualist perspective. She has co-led and co-created provincial community-based early childhood and literacy curriculum in New Brunswick over the past 27 years. 